Article

\title{
Women Remain at Risk of Iodine Deficiency during Pregnancy: The Importance of Iodine Supplementation before Conception and Throughout Gestation
}

\author{
Kristen L. Hynes ${ }^{1}, *\left(\mathbb{D}\right.$, Judy A. Seal ${ }^{2}$, Petr Otahal ${ }^{1}$, Wendy H. Oddy ${ }^{1}$ and John R. Burgess ${ }^{3}$ \\ 1 Menzies Institute for Medical Research, University of Tasmania, Private Bag 23, Hobart, TAS 7001, Australia; \\ Petr.Otahal@utas.edu.au (P.O.); Wendy.Oddy@utas.edu.au (W.H.O.) \\ 2 Public Health Services, Department of Health and Human Services, Tasmanian Government, GPO Box 125, \\ Hobart, TAS 7001, Australia; Judy.Seal@health.tas.gov.au \\ 3 School of Medicine, University of Tasmania, Private Bag 34, Hobart, TAS 7001, Australia; \\ j.burgess@utas.edu.au \\ * $\quad$ Correspondence: K.L.Hynes@utas.edu.au; Tel.: +61-3-6226-7741
}

Received: 27 November 2018; Accepted: 1 January 2019; Published: 15 January 2019

check for updates

\begin{abstract}
In Australia, pregnant women are advised to take an iodine supplement (I-supp) $(150 \mu \mathrm{g} /$ day) to reduce risks to the foetus associated with iodine deficiency (ID). To examine the impact of this recommendation on iodine status, and to identify factors that contribute to adequacy during gestation, supplement use and Urinary Iodine Concentration (UIC) was measured in 255 pregnant women (gestation range 6 to 41 weeks) in Tasmania. The median UIC (MUIC) of $133 \mu \mathrm{g} / \mathrm{L}$ (Inter-quartile range 82-233) was indicative of ID, being below the 150-249 $\mu \mathrm{g} / \mathrm{L}$ range for adequacy during pregnancy. Women taking an iodine-containing-supplement (I-supp) had a significantly higher MUIC $(155 \mu \mathrm{g} / \mathrm{L})(n=171)$ compared to the combined MUIC $(112.5 \mu \mathrm{g} / \mathrm{L})(n=84)$ of those who had never $(120 \mu \mathrm{g} / \mathrm{L})(n=61)$ or were no longer taking an I-supp $(90 \mu \mathrm{g} / \mathrm{L})(n=23)(p=0.017)$. Among women reporting I-supp use, the MUIC of those commencing the recommended $150 \mu \mathrm{g} / \mathrm{day}$ prior to conception was significantly higher than those starting supplementation following pregnancy confirmation: $196(98-315) \mu \mathrm{g} / \mathrm{L}(n=45)$ versus $137.5(82.5-233.5) \mu \mathrm{g} / \mathrm{L}(n=124), p=0.032$. Despite recommendations for iodine supplementation pregnant Tasmanian women remain at risk of ID. Commencing an I-supp of $150 \mu \mathrm{g}$ /day prior to conception and continuing throughout pregnancy is required to ensure adequacy. Timely advice regarding the importance of adequate iodine nutrition, including supplementation is needed to reduce the risk of irreversible in utero neurocognitive damage to the foetus.
\end{abstract}

Keywords: iodine nutrition; iodine deficiency; pregnancy; supplementation; public health; pre-conception

\section{Introduction}

The risk of endemic iodine deficiency (ID) has been well characterised in the south-eastern Australian states of New South Wales (NSW), Victoria (VIC) and Tasmania (TAS) [1,2]. To address public health concerns of inadequate iodine status in Australia and New Zealand mandatory replacement of salt with iodised salt in bread was introduced in 2009 [3]. A series of urinary iodine surveys of Tasmanian school-age children, who are used as a proxy for the general population, indicates that bread fortification has successfully increased iodine status from deficiency to adequacy [4]. However, fortification has had little impact on the status of pregnant women, increasing the pre-fortification median urinary iodine concentrations (MUIC) from $76 \mu \mathrm{g} / \mathrm{L}$ to $86 \mu \mathrm{g} / \mathrm{L}$ [5], well below 
the World Health Organization (WHO) $150-249 \mu \mathrm{g} / \mathrm{L}$ range for adequacy in pregnancy [6]. Similar results have been reported elsewhere $[7,8]$.

Adequate iodine nutrition is essential during pregnancy for foeto-maternal production of thyroid hormones required for optimal foetal neurodevelopment. The consequences of severe iodine deficiency (ID) include spontaneous abortion, stillbirth, congenital abnormalities and endemic cretinism [6]. Increasing evidence suggests that even transient, mild gestational ID has subtle negative impacts, including reductions in IQ [9], educational outcomes [10,11] and language skills [12,13].

Dietary iodine requirements rise by approximately $50 \%$ during pregnancy, driven by increased thyroid synthetic demands, increased renal iodine clearance, and transfer of iodine and thyroxine to the foetus [14]. National Health and Medical Research Council (NHMRC) guidelines recommended that the daily intake (RDI) of iodine for adolescents and adults increase from $150 \mu \mathrm{g} /$ day to $220 \mu \mathrm{g} /$ day during pregnancy [15]. In regions classified as mildly or borderline deficient, pregnant women may have difficulty increasing their level of iodine intake to provide sufficient nutrition for the developing foetus, and pregnant women, and in some cases women of child-bearing age, are iodine deficient despite the general population being considered sufficient $[16,17]$.

Recognition that the current mandatory bread fortification program alone is insufficient to meet the increased demand during pregnancy, the NHMRC introduced recommendations in 2010 for pregnant and breastfeeding women, and women planning pregnancy, to take a daily iodine supplement of $150 \mu \mathrm{g} /$ day to help meet the $220 \mu \mathrm{g} /$ day RDI [18]. It advises supplementation "from the point of planning pregnancy" or "as soon as possible after" confirmation of pregnancy, with supplementation continuing throughout pregnancy and breastfeeding.

We report the iodine status of a group of pregnant Tasmanian women following the introduction of mandatory bread fortification and recommendations for iodine supplementation, and discuss factors contributing to adequate iodine nutrition during gestation.

\section{Materials and Methods}

WHO sentinel surveillance techniques, employed globally to assess and monitor iodine nutrition within populations [6], were used. A convenience sample of pregnant women residing in the southern Tasmanian region were recruited at Royal Hobart Hospital antenatal clinics, and via social media and conventional advertising, as part of a larger investigation (Tasmanian Women's Iodine Nutrition Knowledge (TWINK) Study). Women at all stages of gestation were eligible. To ascertain the iodine status of women of reproductive age, a representative sample of women residing in the same local government areas as the pregnancy group were selected from the Tasmanian electoral roll. Non-pregnant, non-lactating women were eligible. Participants provided a spot urine sample for urinary iodine concentration (UIC) assessment and completed a questionnaire on enrolment. Use and dose of dietary supplements containing iodine (I-supp) during pregnancy and prior to conception was recorded. As retrospective recording of the precise time that supplementation was started is subject to recall bias, iodine supplementation start time is reported dichotomously as "Before" and "After" conception. In Australia, a large variety of over-the-counter nutritional supplements containing iodine are available in tablet, capsule and liquid form, including supplements marketed specifically for pre-conception, pregnancy and lactation, as well as many multi-vitamin formulations that include iodine. Differences in the active amount of iodine and dosage recommendations result in a range of recommended daily doses. To determine compliance with the NHMRC recommendation of $150 \mu \mathrm{g} /$ day [18], participants were asked to provide information on the brand and the daily dose of all nutritional supplements they were taking. At the end of the enrolment visit each participant was provided with a copy of the 2010 NHMRC recommendations for iodine supplementation during pregnancy. Additional spot urine samples and information on I-supp use was collected during each remaining trimester. To determine the median UIC in this sample of women, only data collected at enrolment is reported here as it is probable that provision of the NHMRC recommendations, and indeed participation in the study, led to changes in behaviour with regard to supplement use and 
intake of iodine from dietary sources. Inclusion of samples collected after enrolment could give a false indication of the median UIC in this sample.

UIC was determined at the Institute of Clinical Pathology and Medical Research (Westmead Hospital, Sydney, Austrilia), which complies with IOS/IEC standard 17025, using the modified Sandell-Kolthoff reaction. Iodine status was defined using WHO classifications [6], where a MUIC between 150-249 $\mathrm{\mu g} / \mathrm{L}$ during pregnancy is adequate; and general population adequacy is classified as a MUIC between 100-199 $\mu \mathrm{g} / \mathrm{L}$, with less than $20 \%$ below $50 \mu \mathrm{g} / \mathrm{L}$.

Stata/SE 15.1 (StataCorp LLC, College Station, TX, USA) was used for statistical analysis. UIC is skewed, thus median and interquartile range (IQR) are presented. Means and standard deviations (SD) are used for continuous measures and percentages for categorical measures. $p$-Values were calculated using two-sample Mann-Whitney test of difference between MUIC for two groups, and Krushal-Wallis equality of populations rank test for three or more groups.

The study was approved by the Tasmanian Health and Medical Human Research Ethics Committee (\#H0013336) and participants gave informed written consent.

\section{Results}

\subsection{Iodine Status of Pregnant Women}

Two-hundred and fifty-five pregnant women were recruited between March 2014 and November 2015. The MUIC at enrolment was 133 (IQR 82-233) $\mu \mathrm{g} / \mathrm{L}$ (Table 1). MUIC was highest in the group of women who enrolled during the first trimester and lowest in the group of women who enrolled in the third trimester with the third trimester MUIC being significantly lower than the first (161 vs. $119 \mu \mathrm{g} / \mathrm{L}$, $p=0.046)$.

Table 1. Characteristics of pregnant women $(n=255)$ at enrolment and associated group median urinary iodine concentration (MUIC).

\begin{tabular}{|c|c|c|c|}
\hline Characteristic & $\begin{array}{l}\text { Mean (Standard Deviation) and } \\
\text { Range, or Percentage }(n / N)\end{array}$ & $\operatorname{MUIC}^{1}(\mathrm{IQR}) \mu \mathrm{g} / \mathrm{L}$ & $p$-Value ${ }^{2}$ \\
\hline All participants & & $133(82-233)$ & \\
\hline Age (years) & $29.3(6.0) 15-45$ & & \\
\hline Gestational Age (weeks) & $21.1(8.3) 6-41$ & & \\
\hline \multicolumn{4}{|l|}{ Trimester: } \\
\hline T1 (0-13 weeks) & $16.5 \%(42 / 255)$ & $161(92-233)$ & \\
\hline T2 (14-26 weeks) & $56.5 \%(144 / 255)$ & $137.5(81.5-243)$ & \\
\hline T3 ( $\geq 27$ weeks) & $27.0 \%(69 / 255)$ & $119(78-185)$ & 0.115 \\
\hline \multicolumn{4}{|c|}{ Highest Level of Education Completed: } \\
\hline Year 10 or less & $19.8 \%(50 / 253)$ & $137.5(82-247)$ & \\
\hline >Year 10 & $80.2 \%(203 / 253)$ & $129(82-233)$ & 0.851 \\
\hline \multicolumn{4}{|l|}{ First Pregnancy: } \\
\hline Yes & $36.0 \%(91 / 253)$ & $111(79-222)$ & \\
\hline No & $64.0 \%(162 / 253)$ & $140(86-236)$ & 0.206 \\
\hline \multicolumn{4}{|l|}{ Intention to breastfeed: } \\
\hline Yes & $89.6 \%(223 / 249)$ & $121(87-233)$ & \\
\hline No & $10.4 \%(26 / 249)$ & $133(81-235)$ & 0.765 \\
\hline \multicolumn{4}{|l|}{ Previous miscarriage: } \\
\hline Yes & $31.4 \%(77 / 245)$ & $122(81-235)$ & \\
\hline No & $68.6 \%(168 / 245)$ & $137.5(82.5-231.5)$ & 0.793 \\
\hline \multicolumn{4}{|c|}{$\begin{array}{l}\text { Number of Children } \\
\text { (excluding current pregnancy): }\end{array}$} \\
\hline 0 & $43.3 \%(106 / 245)$ & $112(79-222)$ & \\
\hline 1 & $33.1 \%(81 / 245)$ & $140(83-243)$ & \\
\hline 2 & $16.3 \%(40 / 245)$ & $152(87.5-226)$ & \\
\hline $3-6$ & $7.4 \%(18 / 245)$ & $175.5(95-398)$ & 0.455 \\
\hline
\end{tabular}




\subsection{Iodine Supplement Use}

Two-thirds ( $n=171)$ of participants, were taking an I-supp at enrolment, with 149 (87\%) of these taking the recommended dose of $150 \mu \mathrm{g}$ /day or more (Table 2). The mean daily dose of iodine from supplements was 178 (SD 67.4) $\mu \mathrm{g}$ /day and ranged between 43 to $500 \mu \mathrm{g} /$ day. The percentage of participants using an I-Supp at enrolment was similar across all trimesters, with only a small decline in use from the first to the third trimester.

Table 2. Iodine status of pregnant Tasmanian women categorised by iodine supplement use, dose and timing, and trimester at enrolment. Defined by median urinary iodine concentration (MUIC) and by percentage and number $<150 \mu \mathrm{g} / \mathrm{L}$.

\begin{tabular}{|c|c|c|c|}
\hline Category & MUIC $^{1}$ (IQR) $\mu \mathrm{g} / \mathrm{L}$ & $p$-Value ${ }^{2}$ & $\%<150 \mu \mathrm{g} / \mathrm{L}^{3}(n)$ \\
\hline All participants $(n=255)$ & $133(82-233)$ & & $55.3 \%(141)$ \\
\hline \multicolumn{4}{|l|}{ I-Supp Use: } \\
\hline Never $(n=61)$ & $120(79-207)$ & & $65.6 \%(40)$ \\
\hline Ever $(n=194)$ & $135(85-235)$ & 0.208 & $52.1 \%(101)$ \\
\hline No longer taking $(n=23)$ & $90(70-151)$ & & $73.9 \%(17)$ \\
\hline Still taking $(n=171)$ & $155(86-247)$ & 0.020 & $49.1 \%(84)$ \\
\hline \multicolumn{4}{|c|}{ Among those still taking an I-supp $(n=171)$} \\
\hline \multicolumn{4}{|l|}{ Dose $^{4}:$} \\
\hline$<150 \mu \mathrm{g} /$ day $(n=20)$ & $104(80.5-243.5)$ & & $55.0 \%(11)$ \\
\hline$=150 \mu \mathrm{g} /$ day $(n=93)$ & $153(90-233)$ & & $49.5 \%(46)$ \\
\hline$>150 \mu \mathrm{g} /$ day $(n=56)$ & $182(86-303)$ & $0.350^{5}$ & $44.6 \%(25)$ \\
\hline \multicolumn{4}{|l|}{ Timing: } \\
\hline After Conception $(n=123)$ & $135(82-234)$ & & $52.0 \%(64)$ \\
\hline Before Conception $(n=48)$ & $193(97.5-314.5)$ & 0.046 & $41.7 \%(20)$ \\
\hline \multicolumn{4}{|l|}{ Dose ${ }^{4}$ and Timing: } \\
\hline After Conception \& <150 $(n=18)$ & $104(78-304)$ & & $55.6 \%(10)$ \\
\hline After Conception $\& \geq 150(n=104)$ & $140(84-233.5)$ & & $51.0 \%(53)$ \\
\hline Before Conception \& $<150(n=2)$ & $131(95-167)$ & & $50.0 \%(1)$ \\
\hline Before Conception $\& \geq 150(n=45)$ & $196(98-315)$ & $0.032^{6}$ & $40.0 \%(18)$ \\
\hline \multicolumn{4}{|l|}{ By Trimester: } \\
\hline \multicolumn{4}{|c|}{ I-supp started After Conception $(n=123)$ : } \\
\hline T1 $(0-13$ weeks $)(n=21)$ & $184(100-235)$ & & $33.3 \%(7)$ \\
\hline T2 (14-26 weeks) $(n=71)$ & $158(81-244)$ & & $49.3 \%(35)$ \\
\hline T3 $(\geq 27$ weeks $)(n=31)$ & $98(77-161)$ & 0.068 & $71.0 \%(22)$ \\
\hline \multicolumn{4}{|c|}{ I-supp started Before Conception $(n=48)$ : } \\
\hline T1 ( $0-13$ weeks $)(n=9)$ & $144(85-209)$ & & $55.6 \%(5)$ \\
\hline T2 (14-26 weeks) $(n=27)$ & $221(114-373)$ & & $33.3 \%(9)$ \\
\hline T3 ( $\geq 27$ weeks) $(n=12)$ & $162.5(86-266)$ & 0.329 & $50.0 \%(6)$ \\
\hline
\end{tabular}

\footnotetext{
${ }^{1}$ Median urinary iodine concentration (MUIC) and Interquartile Range (IQR) reported. MUICs within the adequate range shown in bold; ${ }^{2} p$-values for Two-sample Mann-Whitney test of difference in UIC between two groups, or Krushal-Wallis equality of populations rank test for difference in UIC for three groups. $p$-Values less than 0.05 are shown in bold; ${ }^{3}$ Refers to the percentage (and number) of participants with a UIC less than $150 \mu \mathrm{g} / \mathrm{L} ;{ }^{4}$ Dose information unavailable for $n=2$ participants; ${ }^{5}$ For Dose, the groups compared are $<150$ and $>150$ (i.e., $=150$ and $>150$ combined); ${ }^{6}$ For Dose and Timing, the groups compared are the last category (Before Conception \& $\geq 150$ ) vs. the first three categories combined (MUIC 137.5 (82.5-233.5)) (i.e., After Conception \& <150; After Conception \& $\geq 150$, and; Before Conception \& $<150$ ).
}

Those women still taking an I-supp at enrolment had a higher iodine status $(155 \mu \mathrm{g} / \mathrm{L}, n=171)$ than those who had never $(120 \mu \mathrm{g} / \mathrm{L}, n=61)$, or were no longer taking an I-supp $(90 \mu \mathrm{g} / \mathrm{L} n=23)$; the combined MUIC of these groups was indicative of ID (112.5 (77-190.5) $\mu \mathrm{g} / \mathrm{L}, n=84)$ and was significantly lower than the group still taking an I-supp $(p=0.017)$.

Among those still taking an I-supp, only those who started before conception, and took the recommended dose of $150 \mu \mathrm{g} /$ day, or greater, attained adequacy. The MUIC of this group (196 (98-315) 
$\mu \mathrm{g} / \mathrm{L}, n=45)$ was significantly higher than that of the other three dose and timing groups combined (137.5 (82.5-233.5) $\mu \mathrm{g} / \mathrm{L}, n=124, p=0.032)$.

Comparing those still taking I-supps, the decline observed in MUIC across trimesters was only evident among those who started an I-supp post-conception. In this group, the third trimester MUIC was significantly lower than the first trimester ( $184 \mathrm{vs} .98 \mu \mathrm{g} / \mathrm{L}, p=0.032)$. Among those who took an I-supp prior to conception, the MUIC did not decline, but remained close to or within the adequate range throughout pregnancy.

\subsection{Iodine Status of Non-Pregnant/Non-Lactating Women of Reproductive Age}

Sixty-three non-pregnant, non-lactating women, aged 21-50 years, participated. Their MUIC was $79(48-135) \mu \mathrm{g} / \mathrm{L} ; 27.0 \%$ (17/63) were $<50 \mu \mathrm{g} / \mathrm{L}$, with 31.8\% (20/63) between 100-199 $\mu \mathrm{g} / \mathrm{L}$, and; $81.0 \%(51 / 63)$ were $<150 \mu \mathrm{g} / \mathrm{L}$. The MUIC of women taking an I-supp $(n=10)$ fell within the adequate range, $104.5(84-152) \mu \mathrm{g} / \mathrm{L}$, but was not significantly higher than those who did not take an I-supp $(73(45-124) \mu \mathrm{g} / \mathrm{L} n=53, p=0.214)$.

\section{Discussion}

Our results indicate Tasmanian women continue to be at risk of ID in pregnancy. However, we show that iodine supplementation consistent with NHMRC recommendations [18] can improve iodine nutrition, with our findings underscoring the importance of pre-conception supplementation for ensuring adequacy throughout pregnancy.

ID has also been reported in pregnant women (MUIC $116 \mu \mathrm{g} / \mathrm{L}$ ) across Australia in the 2011-2012 National Health Measures Survey (NHMS) [19]. By contrast, studies in some states have reported MUICs within, or close to, the adequate range (NSW $145.5 \mu \mathrm{g} / \mathrm{L}$ in 2011 and $166 \mu \mathrm{g} / \mathrm{L}$ in 2012 [20]; SA between 172 and $189 \mu \mathrm{g} / \mathrm{L}$ in 2011-2012 [21]). To understand the variation in MUICs in different areas of Australia, consideration must be given to factors influencing iodine status, including differences in consumption of iodine-containing foods, I-supp use, gestational stage, underlying population iodine status (particularly in women of reproductive age) and pre-conception thyroid stores.

In Tasmania, we have previously shown that bread fortification has little impact on pregnancy iodine status [5]. This study indicates that iodine supplementation can improve iodine nutrition to adequate levels. While the overall status of our sample was indicative of ID, women taking supplements in accordance with recommendations were within the adequate range. By contrast, women not taking supplements, whether pregnant or not, had MUICs comparable to those reported in pregnant women surveyed prior to the supplementation recommendations $(86 \mu \mathrm{g} / \mathrm{L})$ [5]. Other Australian studies report similar results. In two NSW [20] cohorts, MUICs were higher among women taking I-supps compared to those who didn't (178 and $202 \mu \mathrm{g} / \mathrm{L}$ vs. 109 and $124 \mu \mathrm{g} / \mathrm{L}$, respectively). In SA [21], higher MUICs, at two gestational time-points, were reported in women taking supplements (152 and $221 \mu \mathrm{g} / \mathrm{L})$ compared to those who didn't (141 and $159 \mu \mathrm{g} / \mathrm{L})$.

Taking I-supps, however, does not guarantee sufficiency during pregnancy. A NSW study conducted prior to fortification and supplementation recommendations, reported higher, but less than adequate, MUIC among women taking I-supps compared to those not (115 and $72 \mu \mathrm{g} / \mathrm{L}$, respectively) [22]. Similarly, studies in VIC [7] and SA [8], spanning the pre/post fortification/supplementation periods, found higher but still inadequate MUICs among those taking I-supps compared to those who didn't (VIC: 121.5 and $64.5 \mu \mathrm{g} / \mathrm{L}$; SA: 89 and $75 \mu \mathrm{g} / \mathrm{L}$ ).

Not all groups taking I-supps reached sufficiency in our study; current I-supp consumption and dose were important predictors of adequacy. Only women still taking an I-supp at enrolment had a MUIC within the adequate range. Among those that had ceased supplementation there was no evidence of any enduring I-supp consumption effect on current iodine status, highlighting the importance of recent intake for maintenance of adequate nutrition and supporting the NHMRC recommendation for daily supplementation throughout pregnancy. We found evidence of a dose-response, with increased levels of supplementation associated with higher MUICs. In accord with 
the NHMRC recommendation, only those taking the suggested daily amount of $150 \mu \mathrm{g} /$ day, or above, reached adequacy. By contrast, groups that had never or were no longer taking an I-supp had MUICs indicative of ID. Condo et al. [21] also report a positive dose-response; MUICs at two gestational time-points were higher in women taking $\geq 150 \mu \mathrm{g} /$ day compared to those taking $<150 \mu \mathrm{g} / \mathrm{day}$ (<20 weeks: 221 vs. $163 \mu \mathrm{g} / \mathrm{L}$, and; 28 weeks: 187 vs. $152 \mu \mathrm{g} / \mathrm{L}$ ). Unlike our study, both dose groups had MUICs within the adequate range.

The dose of I-supps required to assist women reach sufficiency for pregnancy will be influenced by the underlying iodine nutrition of the population. The lower the dietary intake of iodine from food sources, the greater the level of supplementation required. Surveys of school-age children indicate that mandatory fortification has led to adequate iodine nutrition levels in Tasmania [4]. While the NHMRC asserts that "through mandatory fortification, most of the Australian population will get enough iodine, meaning women of child-bearing age should enter pregnancy with adequate thyroid stores" [18], our data for Tasmanian women of reproductive age indicates this may not be the case. Applying $100 \mu \mathrm{g} / \mathrm{L}$ general population adequacy cut-point, the $79 \mu \mathrm{g} / \mathrm{L}$ MUIC with $27.0 \%<50 \mu \mathrm{g} / \mathrm{L}$ is indicative of ID, suggesting that women may be entering pregnancy with sub-optimal thyroid stores. While it can be argued that adult UICs between $60-70 \mu \mathrm{g} / \mathrm{L}$ are equivalent to $100 \mu \mathrm{g} / \mathrm{L}$ in children, due to larger urinary volume outputs in adults [23], we suggest that UICs at this level ill-prepare women entering pregnancy for the increased iodine requirements of gestation. Our finding is similar to national data, where women of child-bearing age in the 2011-2012 NHMS [19,24] had lower iodine levels than children and other adults. Although the MUICs (Australia $121 \mu \mathrm{g} / \mathrm{L}$; Tasmania $105 \mu \mathrm{g} / \mathrm{L}$ ) were within the adequate range for non-pregnant/non-breastfeeding women, the report [24] raised concerns that mandatory fortification may not be meeting the needs of women of child-bearing age. Concerningly, $18.3 \%$ of women across Australia had UICs $<50 \mu \mathrm{g} / \mathrm{L}$, which approaches the $20 \%$ cut-point indicative of insufficient iodine intake.

Further evidence that Tasmanian women are entering pregnancy with inadequate thyroid stores is provided by the changes in MUIC as pregnancy progresses. Studies show that UICs, which increase early in pregnancy, follow two patterns as pregnancy progresses, depending upon the underlying population iodine status [25]. In populations where ID exists MUICs in the 2nd and 3rd trimesters decline, often falling below adequate levels. The decline is less marked in iodine sufficient populations with MUICs usually remaining within the optimal range throughout gestation. The pattern observed in our study is indicative of a population with inadequate iodine nutrition. However, among the small number of women who began supplementation prior to conception no decline was evident, with MUICs remaining adequate across trimesters. These observations support the notion that adequate pre-conception thyroid stores, whether attained via iodine from foods, I-supps, or a combination, are essential for maintaining iodine levels throughout pregnancy.

Women in our study who started supplementation after pregnancy did not maintain adequate levels as gestation progressed, suggesting that although supplementation after pregnancy improves UICs, it may not be enough to replenish or maintain thyroid stores that are inadequate prior to conception. A recent UK study found that inadequate pre-conception iodine status (MUIC 108.4 $\mu$ g/L, $17.8 \%<50 \mu \mathrm{g} / \mathrm{L}$ ) was positively associated with poorer cognitive function in the offspring [26]. Given many pregnancies are unplanned, and women may be unaware until well into the first trimester, it is vital that women of child-bearing age have adequate pre-conception iodine nutrition to ensure adequacy for foetal neurodevelopment in early gestation. In populations where iodine intake from dietary sources is inadequate, pre-conception supplementation may improve thyroid stores prior to pregnancy.

Adequate dietary iodine preconception is also important for maintenance of pregnancy, with miscarriage rates known to be higher in regions of severe iodine deficiency [27]. While we found no significant difference in the MUIC of women who had previously had a miscarriage compared to those who had not, the percentage of women (31.4\%) reporting ever having had a miscarriage was higher than expected (up to 25\%) in Australia [28]. While it is beyond the scope of this study to explain 
the high level of miscarriage in our sample, the long-standing existence of iodine deficiency in the Tasmanian population may be an important factor. However, it is not unreasonable to expect some recruitment bias in our sample, with women who have previously had an unexpected outcome in pregnancy being more likely to participate in a study of pregnancy knowledge, because of a heightened interest fuelled by their past experience.

Our study has some limitations. To obtain precise group MUICs from spot urine samples, approximately 125 samples are required to estimate iodine levels with $95 \%$ confidence and $\pm 10 \%$ precision [29]. Although our results are consistent with other studies, care must be taken when interpreting MUICs of small sub-groups. Furthermore, although it is appropriate to use spot samples to determine the median value of a group, UIC is not ideal for classifying individuals, as a single sample may not be indicative of usual status. UIC can vary day-to-day depending upon dietary intake, and while a spot sample reflects ingested iodine over the past $24-\mathrm{h}$, it can be influenced by circadian rhythm and post-meal peaks [30]. For use as an individual measure a minimum of 10 samples are recommended $[29,31]$. Although women in our study provided samples each trimester it was not feasible to collect more and given the confounding effects of gestational stage on UIC taking the average over trimesters is not advisable. Lack of a gold-standard measure of individual status means caution must be exercised when results derived from techniques designed for assessing populations are used to develop public health advice for individuals. Caution is also advised regarding the generalisability of our findings to all pregnant women in Tasmania, or elsewhere in Australia, as recruitment of a volunteer sample may result in selection bias and lack of representativeness. Although our research has previously shown no link between measures of socio-economic status and iodine nutrition [32], our sample was slightly younger than the average pregnant women in Australia (29.3 versus 30.3 years [33]) and more likely to have completed schooling beyond Year 10 compared to Tasmania women of childbearing age [34].

Despite these limitations, it is concerning that in our sample only a small percentage of individuals had UICs within the adequate range. While a single UIC may not indicate usual status, even transient inadequate iodine consumption during pregnancy can have detrimental impacts on the fast-developing foetus. We have demonstrated that even mild maternal ID, defined as a UIC $<150 \mu \mathrm{g} / \mathrm{L}$ at one point during pregnancy, is associated with deficits in educational outcomes that persist into adolescence [11]. Globally, epidemiological studies have linked transient maternal hypothyroidism at crucial times of foetal neurodevelopment to impaired cognitive [9] and psychomotor development [35], behavioural difficulties [36], and abnormal brain morphology [37], with a recent meta-analysis also suggesting that maternal hypothyroxinemia during gestation is associated with lower non-verbal and verbal IQ in the offspring [38]. A randomised controlled trial is needed to facilitate a rigorous examination of the impact of I-supps given a Cochrane review of past trials found " ... there was insufficient data for any meaningful conclusions on the benefits and harms of routine iodine supplementation in women before, during or after pregnancy" [39]. Despite an absence of more robust measures, our study adds to a growing body of evidence suggesting that, even in regions classified as iodine sufficient, women may remain at risk of gestational ID if their intake is inadequate prior to conception and they don't supplement throughout pregnancy. Education about iodine nutrition and the current NHMRC recommendations for supplementation before and during pregnancy to reduce the risk of irreversible long-term, yet preventable, impacts of gestational ID on offspring is needed.

\section{Conclusions}

Despite the introduction of public health measures to address ID in Australia, including mandatory fortification of bread with iodised salt and a recommendation for daily iodine supplementation prior to and throughout pregnancy and breastfeeding, our study indicates that women continue to be at risk of ID during pregnancy. Adequate iodine status was only observed among women who commenced iodine supplementation at the recommended dose prior to conception and 
continued throughout pregnancy. Timely advice about adequate maternal iodine nutrition, including supplementation, is necessary to reduce the risk of neurocognitive damage to the foetus.

Author Contributions: K.L.H. designed the study with assistance from J.R.B. and P.O. Funding acquisition was undertaken by K.L.H., J.A.S. and J.R.B. Data collection and project administration was coordinated by K.L.H. Data preparation and analysis done by K.L.H., with assistance from P.O. K.L.H. interpreted the data and drafted the manuscript with contributions from J.R.B, P.O., J.A.S., and W.H.O.. All authors contributed to and approved the final draft of the manuscript.

Funding: Funding support from the following is gratefully acknowledges: the Tasmanian Community Fund (grant ID 26Medium00084), the Tasmanian State Government Department of Health and Human Services (Epidemiological Research Funding Agreement) and the Royal Hobart Hospital Research Foundation (grant number 14-021). Cost to publish in open access were funded by the Tasmanian State Government Department of Health and Human Services (Translational Research Program Funding Agreement).

Acknowledgments: We express our grateful thanks to all the women who participated in the study, to the research assistants who collected the data (Furley Johnston, Therese Koning and Philippa Terry) and to Sue Bugg for administration support, data entry and cleaning.

Conflicts of Interest: The authors declare no conflict of interest. However, for the record, J.A.S. and J.R.B. are members of the Tasmanian Ministerial Thyroid Advisory Committee, and; the Menzies Institute for Medical Research, University of Tasmania, received funding from the Tasmanian State Government Department of Health and Human Services (DHHS) to conduct the study. Apart from J.A.S., who is employed by DHHS and contributed to the interpretation of the date, writing of the manuscript and the decision to publish the results, no others associated with the funders had any role in the design of the study; in the collection, analyses, or interpretation of data; in the writing of the manuscript, or in the decision to publish the results.

\section{References}

1. Guttikonda, K.; Burgess, J.R.; Hynes, K.; Boyages, S.; Byth, K.; Parameswaran, V. Recurrent iodine deficiency in tasmania, australia: A salutary lesson in sustainable iodine prophylaxis and its monitoring. J. Clin. Endocrinol. Metab. 2002, 87, 2809-2815. [CrossRef] [PubMed]

2. Li, M.; Eastman, C.J.; Waite, K.V.; Ma, G.; Zacharin, M.R.; Topliss, D.J.; Harding, P.E.; Walsh, J.P.; Ward, L.C.; Mortimer, R.H. Are australian children iodine deficient? Results of the australian national iodine nutrition study. Med. J. Aust. 2006, 184, 165-169. [PubMed]

3. Food Standards Australia and New Zealand. Proposal p1003 Mandatory Iodine Fortification for Australia Approval Report [7-08]; Food Standards: Canberra, Australia, 2008.

4. Hynes, K.L.; Seal, J.A.; Otahal, P.; Reardon, M.; Burgess, J.R. Sustained iodine adequacy in tasmania following seven years of mandatory bread fortification. Med. J. Aust. 2018, 208, 126. [CrossRef] [PubMed]

5. $\quad$ Burgess, J.R.; Seal, J.A.; Stilwell, G.M.; Reynolds, P.J.; Taylor, E.R.; Parameswaran, V. A case for universal salt iodisation to correct iodine deficiency in pregnancy: Another salutary lesson from tasmania. Med. J. Aust. 2007, 186, 574-576. [PubMed]

6. World Health Organization (WHO); United Nations International Children's Emergency Fund (UNICEF); International Council for the Control of Iodine Deficiency Disorders (ICCIDD). Assessment of Iodine Deficiency Disorders and Monitoring Their Elimination, 3rd ed.; World Health Organization: Geneva, Switzerland, 2007.

7. Rahman, A.; Savige, G.S.; Deacon, N.J.; Chesters, J.E.; Panther, B.C. Urinary iodine deficiency in gippsland pregnant women: The failure of bread fortification? Med. J. Aust. 2011, 194, 240-243. [PubMed]

8. Clifton, V.L.; Hodyl, N.A.; Fogarty, P.A.; Torpy, D.J.; Roberts, R.; Nettelbeck, T.; Ma, G.; Hetzel, B. The impact of iodine supplementation and bread fortification on urinary iodine concentrations in a mildly iodine deficient population of pregnant women in south australia. Nutr. J. 2013, 12, 32. [CrossRef] [PubMed]

9. Bath, S.C.; Steer, C.D.; Golding, J.; Emmett, P.; Rayman, M.P. Effect of inadequate iodine status in uk pregnant women on cognitive outcomes in their children: Results from the avon longitudinal study of parents and children (alspac). Lancet 2013, 382, 331-337. [CrossRef]

10. Hynes, K.L.; Otahal, P.; Hay, I.; Burgess, J.R. Mild iodine deficiency during pregnancy is associated with reduced educational outcomes in the offspring: 9-year follow-up of the gestational iodine cohort. J. Clin. Endocrinol. Metab. 2013, 98, 1954-1962. [CrossRef] 
11. Hynes, K.L.; Otahal, P.; Burgess, J.R.; Oddy, W.H.; Hay, I. Reduced educational outcomes persist into adolescence following mild iodine deficiency in utero, despite adequacy in childhood: 15-year follow-up of the gestational iodine cohort investigating auditory processing speed and working memory. Nutrients 2017, 9, 1354. [CrossRef]

12. Markhus, M.W.; Dahl, L.; Moe, V.; Abel, M.H.; Brantsaeter, A.L.; Oyen, J.; Meltzer, H.M.; Stormark, K.M.; Graff, I.E.; Smith, L.; et al. Maternal iodine status is associated with offspring language skills in infancy and toddlerhood. Nutrients 2018, 10, 1270. [CrossRef]

13. Abel, M.H.; Brandlistuen, R.E.; Caspersen, I.H.; Aase, H.; Torheim, L.E.; Meltzer, H.M.; Brantsaeter, A.L. Language delay and poorer school performance in children of mothers with inadequate iodine intake in pregnancy: Results from follow-up at 8 years in the norwegian mother and child cohort study. Eur. J. Nutr. 2018, 1-12. [CrossRef]

14. Glinoer, D. The regulation of thyroid function in pregnancy: Pathways of endocrine adaptation from physiology to pathology. Endocr. Rev. 1997, 18, 404-433. [CrossRef] [PubMed]

15. National Health and Medical Research Council. Nutrient Reference Values for Australia and New Zealand Including Recommended Dietary Intakes. Available online: https://www.nrv.gov.au/nutrients/iodine (accessed on 15 October 2018).

16. Iodine Global Network. Global Scorecard of Iodine Nutrition in 2017 in the General Population and in Pregnant Women (pw). Available online: http://www.ign.org/cm_data/IGN_Global_Scorecard_AllPop_ and_PW_May2017.pdf (accessed on 15 October 2018).

17. Wong, E.M.; Sullivan, K.M.; Perrine, C.G.; Rogers, L.M.; Pena-Rosas, J.P. Comparison of median urinary iodine concentration as an indicator of iodine status among pregnant women, school-age children, and nonpregnant women. Food Nutr. Bull. 2011, 32, 206-212. [CrossRef] [PubMed]

18. National Health and Medical Research Council. Iodine Supplementation for Pregnant and Breastfeeding Women; National Health and Medical Research Council: Canberra, Australia, 2010.

19. Australian Institute of Health and Welfare. Monitoring the Health Impacts of Mandatory Folic Acid and Iodine Fortification; Cat. No. Phe 208; Australian Institute of Health and Welfare: Canberra, Australia, 2016.

20. Charlton, K.E.; Yeatman, H.; Brock, E.; Lucas, C.; Gemming, L.; Goodfellow, A.; Ma, G. Improvement in iodine status of pregnant australian women 3 years after introduction of a mandatory iodine fortification programme. Prev. Med. 2013, 57, 26-30. [CrossRef] [PubMed]

21. Condo, D.; Huyhn, D.; Anderson, A.J.; Skeaff, S.; Ryan, P.; Makrides, M.; Muhlhausler, B.S.; Zhou, S.J. Iodine status of pregnant women in south australia after mandatory iodine fortification of bread and the recommendation for iodine supplementation. Matern. Child Nutr. 2016, 13, e12410. [CrossRef] [PubMed]

22. Blumenthal, N.; Byth, K.; Eastman, C.J. Iodine intake and thyroid function in pregnant women in a private clinical practice in northwestern sydney before mandatory fortification of bread with iodised salt. J. Thyroid Res. 2012, 2012, 798963. [CrossRef] [PubMed]

23. Zimmermann, M.B.; Andersson, M. Assessment of iodine nutrition in populations: Past, present, and future. Nutr. Rev. 2012, 70, 553-570. [CrossRef] [PubMed]

24. Australian Bureau of Statistics. 4364.0.55.006-Australian Health Survey: Biomedical Results for Nutrients, 2011. Available online: http:/ /www.abs.gov.au/ausstats/abs@.nsf/Lookup/4364.0.55.006main+ features12011-12 (accessed on 15 October 2018).

25. Smyth, P.P. Variation in iodine handling during normal pregnancy. Thyroid 1999, 9, 637-642. [CrossRef]

26. Robinson, S.M.; Crozier, S.R.; Miles, E.A.; Gale, C.R.; Calder, P.C.; Cooper, C.; Inskip, H.M.; Godfrey, K.M. Preconception maternal iodine status is positively associated with iq but not with measures of executive function in childhood. J. Nutr. 2018, 148, 959-966. [CrossRef]

27. Hetzel, B.S. Iodine deficiency disorders (idd) and their eradication. Lancet 1983, 2, 1126-1129. [CrossRef]

28. Miscarriage Stillbirth and Newborn Death Support (SANDS). Miscarriage. Available online: https://www. sands.org.au/sands-resources/miscarriage (accessed on 21 December 2018).

29. Andersen, S.; Karmisholt, J.; Pedersen, K.M.; Laurberg, P. Reliability of studies of iodine intake and recommendations for number of samples in groups and in individuals. Br. J. Nutr. 2008, 99, 813-818. [CrossRef] [PubMed]

30. Als, C.; Helbling, A.; Peter, K.; Haldimann, M.; Zimmerli, B.; Gerber, H. Urinary iodine concentration follows a circadian rhythm: A study with 3023 spot urine samples in adults and children. J. Clin. Endocrinol. Metab. 2000, 85, 1367-1369. [CrossRef] 
31. Konig, F.; Andersson, M.; Hotz, K.; Aeberli, I.; Zimmermann, M.B. Ten repeat collections for urinary iodine from spot samples or 24-hour samples are needed to reliably estimate individual iodine status in women. $J$. Nutr. 2011, 141, 2049-2054. [CrossRef] [PubMed]

32. Hynes, K.L.; Blizzard, C.L.; Venn, A.J.; Dwyer, T.; Burgess, J.R. Persistent iodine deficiency in a cohort of tasmanian school children: Associations with socio-economic status, geographical location and dietary factors. Aust. N. Z. J. Public Health 2004, 28, 476-481. [CrossRef] [PubMed]

33. Australian Institute of Health and Welfare. Autralia's Mothers and Babies 2015-In Brief; Perinatal Statistics Series No. 33. Cat No. PER91; Australian Institute of Health and Welfare (AIHW): Canberra, Australia, 2017.

34. Australian Bureau of Statistics. Table Builder. Available online: http://www.abs.gov.au/websitedbs/ censushome.nsf/home/tablebuilder (accessed on 21 December 2018).

35. Pop, V.J.; Kuijpens, J.L.; van Baar, A.L.; Verkerk, G.; van Son, M.M.; de Vijlder, J.J.; Vulsma, T.; Wiersinga, W.M.; Drexhage, H.A.; Vader, H.L. Low maternal free thyroxine concentrations during early pregnancy are associated with impaired psychomotor development in infancy. Clin. Endocrinol. 1999, 50, 149-155. [CrossRef]

36. Abel, M.H.; Caspersen, I.H.; Meltzer, H.M.; Haugen, M.; Brandlistuen, R.E.; Aase, H.; Alexander, J.; Torheim, L.E.; Brantsaeter, A.L. Suboptimal maternal iodine intake is associated with impaired child neurodevelopment at 3 years of age in the norwegian mother and child cohort study. J. Nutr. 2017, 147, 1314-1324. [CrossRef]

37. Clairman, H.; Skocic, J.; Lischinsky, J.E.; Rovet, J. Do children with congenital hypothyroidism exhibit abnormal cortical morphology? Pediatr. Res. 2015, 78, 286-297. [CrossRef]

38. Levie, D.; Korevaar, T.I.M.; Bath, S.C.; Dalmau-Bueno, A.; Murcia, M.; Espada, M.; Dineva, M.; Ibarluzea, J.M.; Sunyer, J.; Tiemeier, H.; et al. Thyroid function in early pregnancy, child iq, and autistic traits: A meta-analysis of individual participant data. J. Clin. Endocrinol. Metab. 2018, 103, 2967-2979. [CrossRef]

39. Harding, K.B.; Pena-Rosas, J.P.; Webster, A.C.; Yap, C.M.; Payne, B.A.; Ota, E.; De-Regil, L.M. Iodine supplementation for women during the preconception, pregnancy and postpartum period. Cochrane Database Syst. Rev. 2017, 3. [CrossRef]

(C) 2019 by the authors. Licensee MDPI, Basel, Switzerland. This article is an open access article distributed under the terms and conditions of the Creative Commons Attribution (CC BY) license (http:/ / creativecommons.org/licenses/by/4.0/). 